\title{
Medical Student Debt Reform: a Proposed Value-Based Loan Repayment Policy
}

\author{
Julia Driessen, $P h D^{7}$, Caitlin Zaloom, $P h D^{2}$, and William H. Shrank, MD, $M S H S^{3}$ \\ ${ }^{1}$ Graduate School of Public Health, University of Pittsburgh, Pittsburgh, PA, USA; ${ }^{2}$ New York University, New York, NY, USA; ${ }^{3}$ Humana, Louisville, KY, \\ USA.
}

The call for value-based medicine has augmented the role of primary care physicians, potentially exacerbating the already-acknowledged shortage of primary care physicians in the current delivery landscape. Lifetime earnings for primary care physicians are millions lower than those for other specialties, and the burden of medical school debt is increasing at a rate that outpaces inflation. Given the societal value of primary care entry for newly minted physicians, one option is a loan repayment program that shares some of that societal value with the physicians themselves, essentially a subsidy that is continuous and tied to present-day specialty choice. While income-based options exist currently, these are merely a proxy for specialty, and other service-driven options are finite and may impose undue burden on physicians at an early and pressureladen time in their careers. Value-based repayment reflects the graduate's benefit from physician training while also rewarding the real-time societal value of specialties such as primary care, allowing doctors to put their talents to their best uses while advancing the transformation of the physician workforce necessary to realize value-based, patient-centered, populationoriented care.

J Gen Intern Med 35(5):1576-8

DOI: $10.1007 / \mathrm{s} 11606-020-05759-5$

(c) Society of General Internal Medicine 2020

$\mathrm{T}$ he call for value-based medicine has become pervasive and an emphasis on aligning provider behavior with financial incentives is now the status quo. Value-based care begins with primary care; we count on these practitioners to manage, prevent, and coordinate medical care in ways that benefit patients and are more cost-effective. The payment reform movement, however, has not yet set its sights on the problem of workforce development and is indeed still grappling with a fee schedule that has been criticized for undervaluing the services most often delivered in primary care. ${ }^{1}$ While the payment reform gears slowly turn in search

No presentations on this topic

Received July 28, 2019

Revised February 12, 2020

Accepted February 19, 2020

Published online March 5, 2020 of a compensation model that rewards care that is "high value," alleviating the burden of medical school debt represents a different approach to altering the financial balance sheet that may improve the appeal of a career in primary care to tomorrow's physicians.

As of 2017, three-quarters of medical school graduates finished with educational debt averaging over $\$ 190,000 .^{2}$ Over the last decade, this burden has increased substantially faster than inflation. ${ }^{3}$ Evidence on the impact of student loan debt on specialty choice is mixed, but with lifetime earnings for primary care physicians that are \$1-3 million less than for physicians in other areas, it is no surprise that debt may drive new doctors toward more financially lucrative specialties. ${ }^{4}$ Compounded with undergraduate education debt, ${ }^{5}$ these punishing numbers may begin to have their effect even earlier in the process too, by shaping who becomes physicians in the first place. While a counterargument may juxtapose the positive long-term return on medical school investment, ${ }^{4}$ to the extent that up-front training debt is a burden, it is disproportionately felt by those physicians entering fields most valued, but least compensated, by society. There is a multiplier effect to such misalignment between the collective vision for value-based medicine and the debt burden that incentivizes specialist entry. Specialists - who might have been primary care providers - are not associated with lower cost of care and have higher levels of use of diagnostics and procedures. ${ }^{6}$

Changing how doctors pay back their loans can help. Right now, newly minted doctors can choose from several loan programs that are intended to make lower-paying but highvalue fields more attractive. ${ }^{7}$ The general flavor of these programs is a pre-established loan offset in exchange for either entering a field with too few practitioners, such as primary care, or practicing for a few years in a health professional shortage area (HPSA). In addition, most federal loans are eligible for income-driven repayment options, which peg repayment to anywhere from 10 to $25 \%$ of discretionary income, with loan forgiveness of the remaining balance after a 20-25year repayment period. Although these programs certainly offer options for reducing the burden of medical school debt, they do not attempt to directly affect decisions about what and where physicians practice long-term-while income may proxy for specialty selection, primary care and specialist 
physicians in high cost-of-living areas may not be assisted any differently. Furthermore, while there is some evidence that these programs have affected physician decision-making, ${ }^{8}$ it may still be more appealing to forgo primary care and/or HPSA service and simply pay off loans by entering a higherpaying specialty. ${ }^{9}$ In 2017 , slightly fewer than half of medical school graduates were planning to enter a loan forgiveness or repayment program. ${ }^{2}$

Medical school loans should embrace value-based repayment models. Such an approach could be real-time and continuous, augmenting the current income-based repayment options with further "value adjustments" to directly incentivize service in high (societal)-value fields such as primary care and geriatrics, rather than relying on income as a proxy or offering short-term or one-time relief. These micro-level modifiers could be derived from macro-level savings estimates associated with further investment in primary care, and serve as real-time subsidies that reflect the societal value of primary care entry. ${ }^{7}$

Such a model would calibrate a value "offset" based on whether a physician is currently deemed to be practicing in primary care or another field deemed to be high-value. "Currently deemed" could be defined a variety of ways, based on factors including self-identified specialty or claims information, such as a provider adaption of the attribution methodology used for accountable care organizations. Based on such criteria, as long as a physician is observed to be practicing in a target field such as primary care, in a given time frame, they would be eligible for the value subsidy. For example, an annual version of our proposed approach would assess whether a provider is observed to be practicing in a "high value" field in the previous year (e.g., via claims), and provide a loan subsidy. In this way, individuals are directly rewarded in realtime for choosing a specialty that aligns with health system needs and priorities.

Such modifiers for societal value would deter potential loopholes of an income-only model, such as rewarding physicians in lower-value fields who earn less because they opt to work less than full-time. Furthermore, our suggested approach is continuous and real-time, without forcing an up-front specialty commitment and instead reflecting and rewarding the present societal contribution of practitioners in high-value fields. This type of valuebased approach would create a flexible and transparent model that purposefully does not reduce medical school tuition in a blanket fashion - the point very much is to direct incentives to specialties deemed of greatest societal value, and thus is arguably better aligned with the delivery system outcomes that current payment reform efforts have in mind. Indeed, recently the Medicare Payment Advisory Commission recommended that Medicare implement a geriatric-specific scholarship or loan repayment program to similarly incentivize physician entry. ${ }^{10}$ An expanded version of such a program would build on the Department of Health and Human Service's existing data and harness the general momentum of value-based reforms. In this way, while such an effort would require defining eligibility and monitoring for gaming or other loopholes, it could adapt the institutional knowledge of using claims to identify delivery of primary care in value-based endeavors such as the Medicare Shared Savings Program accountable care organization model.

Such an approach would also undo the regressive nature of the status quo. In the new system, those who earn more in procedural specialties would be expected to pay more, while those who earn less and focus on population health priorities would pay less. While not directly addressing the other nonpecuniary factors affecting entry into primary care, such as larger panels and compressed visit times, aligning doctors' job preferences with financial rewards would help avoid physician burnout and instead possibly engender intangibles such as altruism and a commitment to "pay-it-forward" reciprocity. Taxpayers will benefit broadly as their subsidy dollars encourage both an efficient use of funds and a better health system. ${ }^{7}$

Today, doctors must repay enormous loans during the earliest, most resource-limited, and most challenging decade of their careers. Value-based repayment could augment the existing income-based repayment models to allow newly minted doctors to be able to make the choices best for them, rebalancing the labor market while promoting population health. This kind of framework is also adaptable, allowing changing criteria for eligible specialties or other categories of demand (e.g., could be adapted to underserved areas) and updated value subsidy amounts as health system priorities and provider composition changes. With a revised student debt system, doctors will be able to put their talents to their best uses while advancing the transformation of the physician workforce necessary to realize value-based, patient-centered, population-oriented care.

Corresponding Author: Julia Driessen, PhD; Graduate School of Public Health University of Pittsburgh, Pittsburgh, PA, USA (e-mail: driessen@pitt.edu).

\section{Compliance with Ethical Standards:}

Conflict of Interest: The authors declare that they do not have a conflict of interest.

\section{REFERENCES}

1. Medicare Payment Advisory Commission. Report to the Congress: Medicare Payment Policy. March 2017.

2. Association of American Medical Colleges. Medical student education: Debt, costs, and loan repayment fact card. 2016.

3. Jolly P. Medical School Tuition and Young Physicians' Indebtedness. Health Aff 2005: 24(2):527-35.

4. Leigh JP, Tancredi D, Jerant A, Romano PS, Kravitz RL. Lifetime earnings for physicians across specialties. Med Care. 2012;50(12):1093101

5. Zaloom C. Indebted: How families make college work at any cost. Princeton, NJ: Princeton University Press; 2019. 
6. Friedberg MW, Hussey PS, Schneider ES. Primary care: a critical review of the evidence on quality and costs of health care. Health Aff 2010. 29(5): 766-772.

7. Friedman AB, Grischkan J, Dorsey ER, George BP. Forgiven but not relieved: US physician workforce consequences of changes to public service loan forgiveness. J Gen Intern Med 31.10 (2016): 1237-1241.

8. Holmes GM. Does the National Health Service Corps improve physician supply in underserved locations? East Econ J 2004. 30(4): 563-581.
9. Marcu MI, Kellermann AL, Hunter C, Curtis J, Rice C, Wilensky G. Borrow or Serve? An Economic Analysis of Options for Financing a Medical School Education. Acad Med 2017. 92(7):966.

10. Medicare Payment Advisory Commission. Report to the Congress: Medicare Payment Policy. June 2019.

Publisher's Note Springer Nature remains neutral with regard to jurisdictional claims in published maps and institutional affiliations. 